Paediatrica Indonesiana $15: 239$ - 246. Sept. - Okt. 1975.

From the Department of Child Health, Sumbar Waras Hospital, University of Tarumanegara, Jaka'rta, Inidonesia

\title{
Disseminated Intravascular Coagulation in Gastroenteritis
}

S. SETIADHARMA and T. HIMAWAN

\begin{abstract}
Four children, 3 males and 1 female, varying in ages from 3 to 12 years, showing the shock syndrome in gastroenteritis accompanied by intnavascular caagulation (DIC) are reported. All pativents developed progressive thrombocytopenia, prolonged prothrombin time as well as partial thromboplastin time; and a decreased content of fibrinagen in the bload several diays after hospitatization was observed. The diagnosis and traatment of DIC are also discussed.
\end{abstract}

Received 30th. Nov. 1974. 


\section{Introduction}

Any severely ill child may develop the complication of disseminated intravascular coagulation (DIC). DIC processes may occur mostly in children with shock, haemorrhagic, septic as well as anaphylactic and burns (Hardaway, 1966). In certain conditions of bacterial or viral infections (McKay and Margaretten, 1967), in premature newborns suffering from respiratory distress syndrome RDS - (Swyer, 1971; Weissbach et al., 1973), and in many other pathological circumstances which have been extensively reviewed by Abildgaard (1969), Karpatkin (1971), McKay (1965), and Rodriquez-Erdmann (1965), this pathological intravascular clotting mechanism was noted; in typhoid fever DIC is not uncommon (Setiadharma and Kho, 1973).

Four patients, 3 males and 1 female, varying in ages from 3 to 12 years, showing the shock syndrome in gastroenteritis accompained by DIC are reported. All patients had some degree of circulatory failure with developing thrombocytopenia, prolonged prothrombin time as well as partial thromboplastin time, and a decreased content of fibrinogen in the blood several days after hospitalization. These are valuable measure for detecting DIC.

\section{Reportt of cases}

Four children, comprising 3 males and 1 female, whose ages ranged from 3 to 12 years, were studied. They were transferred to the Department of Child Health of Sumber Waras Hospital, Jakarta, due to fever, diarrhoea, vomiting and abdominal pain of severail days duration. All patients were severely ill on admission and had some degree of circulatory failure (cold extremities, excessive transpirations, reduced systolic and diastolic pressures) and dehydration. No neurological abnormalities were noted on admission. Torniquet test was applied to all patients. The following coagulation studies were performed: platelet count, prothrombin time according to the one-stage method of Lynch (1969), fibrinogen concentration of the blood according to the method of Stirland (1956), the clotting time according to the method of Lee and White (1913), and the bleeding time done by the method of Duke (Owen, 1969).

All patients were treated with antibiotics parenterally followed by oral administration: Pat, 1 with ampicillin $50 \mathrm{mg} . / \mathrm{kg}$. body weight daily; chloramphenicol $50 \mathrm{mg} \cdot / \mathrm{kg}$. body weight daily given to Pats. 2 and 4; Pat. 3 with tetracycline $40 \mathrm{mg} . / \mathrm{kg}$. body weight daily. The treatment of shock was intensively carried out by infusion of Ringer's lactate solution, 
plasma volume expanders, and blood transfusion (to Pats. 1 and 3), besides the commonly used saline, glucose, and electrolytes solutions. Corticositeroids were administered to 3 patients: Celestone was given intravenously in a dosage of $0.25 \mathrm{mg} . / \mathrm{kg}$. body weight daily; heparin $1 \mathrm{mg}$./ kg. body weight intravenously was given to Pats. 1 and 2 every 4 hours for 2 and 8 days, respectively.

Tables 1 and 2 showed the clinical features, therapy and laboratory examinations respectively of the patients on admission and during hospitalization. All patients showed a significant drop of platelets several days after hospitalization (Table 3 ). The partial thromboplastin time of 3 patients showed a prolongation several days after admission; in Pat. 3 it was already prolonged on the first day of hospitalization (56 seconds). The fibrinogen content of the blood was determined based upon the probaibility of intravascular clotting (Table 4). The clotting time varied from 7 to more than 15 minutes in 3 patients, while in Pat. 2 it was not measured. The bleeding time was abnormal in Pats. 1 and 4 (more than 15 minutes), in Pat. 3 it was 5 minutes on admission, while Pat. 2 showed a normal value (2'30') on the 4th day of hospitalization.

Haematemesis and melaena were in Pats. 1 and 3; haematomas on the sites of injections were noted in Pat. 1. Torniquet tests were negative in all patients except one (Pat. 1). Fecal culture revealed Vibrio Eltor positive in Pat. 3, and Salmonella typhosa was confirmed positive in the blood of Pat. 4.

Hospital course: * Patient 1 died on the 6th day of hospitalization after one day of heparimization; probable cause of death was profuse bleeding as indicated by the fall of the hemogloibin content of $11 \mathrm{gm} . \%$ on admission to $6.5 \mathrm{gm} \%$ on the 5th day of hospitalization, although blood transfusion had been given.

* In Pat. 2 (female, 3 years old) the fibrinogen content was still low (84 mg.\%) after heparin administration, although the blood platelet count and prothrombin time were increasing, respectively 336,000 per cu.mm. and $64 \%$. This patients died on the 14 th day of hospitalization.

* Patient 3 (male, 12 years old) with positive Eltor in the fecal culture showed a significant drop of platelet count $(19,020$ per cu.mm.) on the 4th day of hospitalization. Heparin was not yet administered as the patient died aue to irreversible circulatory failure on the day when DIC was detected.

* Patient 4 (male, 8 years old), confirmed typhoid fever by blood culture, did show thrombocytopenia of 78,000 cu.mm. on admission and a progressive reduction of 36,000 blood platelets/cu.mm. on the 2 nd day of hospitalization. Hypofibrinogenaemia 
of $44 \mathrm{mg} . \%$ on the 2 nd day after admission was noted. Both bleeding and clotiing time were prolonged (more than 15 minutes). The patient did not show any signs of bleeding on the skin. The Rumpel-Leede test was negative. Celestone was added to the intravenous fluid and electrolytes administration. Heparinization was not performed in this case. The patient recovered after 16 days of hospitalization.

\section{Discussion}

The patients presented were in shock: reduced systolic and diastolic blood pressures, cold extremities, and excessive transpiration. DIC was diagnosed on the following criteria: Shock accompained by a sudden drop of previously normal blood platelet count (McKay, 1965), prolonged prothrombin and partial thromboplastin time, reduced fibrinogen level in the blood, and alterations of the red blood cells. These are valuable measures for the early detection of DIC.

Other coagulation studies (BraticMikes and Mikes, 1973) and the presence of fibrin split products (FSP) are found to be non-reliable indicators, as this latter matter is also found in other circumstances without the occurence of DIC, e.g. in renal and hepatic disorders, thrombotic thrombocytic purpura ( $\mathrm{Ha}-$ thaway, 1970). Peripheral blood smear examinations may show bur- red and fragmented red blood cells, possibly caused by the passing of the erythrocytes through the meshes of intravascular fibrin (Rudenberg et al., 1968). Blood clotting defects may be deficiency of multiple coagulation factors (factors $\Pi, V$, VIII, IX, X, $\mathrm{XI})$. These factors may become reduced to levels inadequate for haemostasis because they are being used up more rapidly than they can be produced.

Disseminated intravascular coagulation may develop in any severely ill child, mostly in those showing the shock syndrome. The recognition of DIC process is very important as an early successful diagnosis and treatment to prevent death, although the mortality rate still remains high. The authors are convinced of the important role of shock as a trigger mechanism in the development of DIC as intravascular clotting is frequently associated with endotoxin shock. Experimentally, according to Mason et all (1970), endotoxin has been shown to activate Hageman factor (factor XIII, also called the fibrin stabilizing enzyme) and destroy platelets (Cohen et al., 1965). Weil and Shubin (1967) stated that the mechanism of endotoxin shock was a reaction in the plasma of a sensitized antigen with an antibody and a bacterial endotoxin, resulting in the production of histamin, slow reactive substance $A$, and bradykinin. These 
substances will lead to arteriolar dilatation, venular constriction, increased capillary permeability, and consequently arterial hypotension. Decreased cardiac output accompanied bry simultaneous opening of all capillaries at one time results in extremely slow capillary blood flow. This slow blood flow results in hypoxaemia and enhances lactic acid formation resulting in acidosis. As slow circulating acid blood is hypercoaguable (Hardaway et al., 1962), there will be a vicious cycle of shock and the development of intravascular clotting defects.

Hypofibrinogenaemia, frequently found in DIC (McKay, 1965), was noted in our patients. The most important management is the administration of proper antibiotics for the underlying diseases (Karpatkin, 1971), and the treatment of shock. Corticosteroids have played an important role in the management of shock in general, especially in endotoxin shock. Abildgaard (1969) suggested that corticosteroids should be added to the treatment of the shock syndrome, especially if heparin was given. Heparin may be a useful therapeutic agent in the treatment of DIC, but it must be given as early as possible. Corrigan and Jordan (1970) showed that heparinization may correct the coagulation abnormalities occuring in DIC, but the mortality rate still remains high for patients with the shock syndrome. The control of DIC does not. increase survival, and it seems that heparin may not be the most important factor in abolishing intravascular clotting. The role of heparin therapy in treating this condition awaits further studies.

In conclusion, the following suggestions to the severely ill patients with the shock syndrome can be recommended:

1. estimation of thrombocytes and, if possible, coagulation factors;

2. treatment of shock with adequaite fluids and electrolytes intravenously, plasma volume expanders, and/or blood transfusions;

3. vasoactive argents such as Effortil;

4. administration of corticosteroids in high doses;

5. heparin $1 \mathrm{mg} . / \mathrm{kg}$. body weight intravenously every 4 hours; and,

6. proper antibiotic therapy for the underlying disease. 
TABL田 1 : Clinical features and therapy of Gastroenteritis with DIC.

\begin{tabular}{l|c|c|c|c}
\hline & BS. & OS. & U. & SA. \\
\hline Bload pressure & $90 / 70$ & $90 / 00$ & $90 / 30$ & $90 / 60$ \\
Fever & + & + & + & + \\
Vomiting & + & - & + & - \\
Diarrhoea & + & + & + & + \\
Abdiominal pain & + & - & + & + \\
Haematemesis & + & - & + & - \\
Mellaena & + & - & + & - \\
Haematoma & + & - & - & - \\
Petechiae & - & - & - & - \\
Rumpel-Leede & + & - & - & - \\
Corticosteraids & + & - & + & + \\
Heparin & + & + & - & - \\
Antibiotics & + & + & + & + \\
Died & + & + & + & - \\
\hline
\end{tabular}

TABLE 2 : Peripherai bload examinations, fecal and blood cultures of patients with DIC in Gastroenteritis.

\begin{tabular}{l|r|r|r|c}
\hline & BS. & OS. & U. & SA. \\
\hline Age (in years) & 4 & 3 & 12 & 8 \\
Haemoglobin (gm.\%) & 11 & 12 & 16.5 & 11.8 \\
Hrematocrit (vol.\%) & 36 & 42 & 42 & 35 \\
W.B.C./cu.mm. & 4,300 & 7,000 & 21,000 & 4,500 \\
Cultures: & & & & \\
$\quad$ Fecal & - & - & v. Eltor & S. Typhosa \\
Blood & - & - & - & \\
\hline
\end{tabular}


TABLE 3 : Thrombocytopenia in patients with Gastroenteritis with DIC.

\begin{tabular}{l|c|c|c}
\hline \multirow{2}{*}{ Patients } & \multicolumn{2}{|c|}{ Number of platelets/cu. mm. } & $\begin{array}{c}\text { occurence in days } \\
\text { after admission }\end{array}$ \\
\cline { 2 - 4 } & on admission & after admission & 3 \\
1. BS & 156,000 & 4,000 & 3 \\
2. OS & 156,000 & 96,000 & 4 \\
3. U & 300,000 & 19,000 & 2 \\
4. SA & 78,000 & 36,000 & \\
\hline
\end{tabular}

TABLE 4: Hypofibrinogenaemia in Gastroenteritis toith DIC.

\begin{tabular}{l|c|c|c}
\hline \multirow{2}{*}{ Patients } & \multicolumn{2}{|c|}{ Fibrinogen concentration in mg. \% } & $\begin{array}{r}\text { occurence in days } \\
\text { after admission }\end{array}$ \\
\cline { 2 - 4 } & on admission & after admission & 3 \\
\hline 1. BS & not done & 118 & 4 \\
2. OS & not done & 95 & 10 \\
3. U & 472 & 84 & 4 \\
& & 13 & 2 \\
4. SA & not done & 44 & \\
\hline
\end{tabular}

\section{REFERENCES}

1. ABILDGAARD, C.F.: Recogmition and treatment of intravascular coagulation. J. Pediatr., 74 : 164 (1969).

2. BRATIC-MIKES, V. and MIKES, A.: Laboratory screening for Disseminated Intravascular Coagulation. Abstract Second Haemaitol. Meeting, Vienna, p. 277 (1973).

3. COHEN, P. BRAUNWALD, J. and GARDNER, F.H.: Destruction of canin and rabbit platelets following intravenous administration of carbon particles endotoxin. J. Lab. clin. Med. $66: 263$
(1965), cited from GERARD et al. (1973).

4. CORRIGAN, J.J. and JORDAN, C.M.: Heparin therapy in septicemia with disseminated intravascular coagulation $\mathrm{N}$. Engl. J. Med. 283 : (1970).

5. GERARD, P.: purpura. J. Pediatr. 82 : 780 (1973).

6. HARDAWAY, R.M.: Syndromes of Disseminated Intravascular Coagulation. (Thomas, springfield, III. 1966).

7. HARDAWAY, R.M. et al.: Studies on the role of intravascular coagulation in 
Irreversible hemorrhagic shock. Ann. Surg. 155 : 241 (1962).

8. HATHAWAY, W.E.: Care of the critically ill child: the problem of Disseminated Intravascular Coagulation. Pediatrics 5 : 771 (1970).

10. LEE, R.I. and WHITE, P.D.: A clinical study of the coagulation time of blood. Am. J. Med. Sci. 145 : 495 (1913).

11. LYNCH, M.J.: Medical Laboratory Technology and Clinical Pathology (Saunders, Philadelphia 1969).

12. MASON, J.W.;KLEEBERG, U.; DOLAN, R. and COLMAN, R. W.: Plasma kallikrein and Hageman factor in Gram-negative bacteria. Ann. intern. Med. $73: 545$ (1970).

13. McKAY, D.G.: Disseminated Intravascular Coagulation; an intermediary mechanism of disease. (Hoeber, New

- York 1965).

14. McKAY, D.G. and MARGARETTEN, W.: Disseminated intravascular coagulation in viral diseases. Arch. intern. Med. $120: 129$ (1967).

15. OWEN, C.A. et al.: The Diagnosis of Bleeding Disorders (Churchill, London 1969).

16. QUICK, A.J.: Determination of prothrombin. Am: J. Med. Sci. 190 : 501 (1935).

17. RODRIQUEZ-ERDMANN, F.: Bleeding due to increased intravascular blood coagulation: haemorrhagic syndromes caused by consumption of blood-clotting factors (consumption coagulopathies). N. Eng. J. Med. 273: 1370 (1965).

18. RUBENBERG, M.L. et al.: Microangiopathic haemolytic anaemia: the experimental production of haemolysis and red-cell fragmentation by defibrination in ! vivo. Brit. J., Haematol. $14: 627$ (1968).

19. SETIADHARMA, S. and KHO, L.K.: Disseminated intravascular coagulation in typhoid fever in childhood. Southeast Asian J. trop. Med. Publ. Hlth. 4 : 461 (1973).

20. STIRLAND, R.M.: A rapid method of estimating fibrimogen. Lancet 672 (1965)

21. SWYER, P.R.: The clinical features and management of the seriously ill newborm, in JONES and OWEN-THOMA.S' Care of the oritically ill child, p. 198 (Arnold, London 1971).

22. WEIL, MH. and SHUBIN, H.: Diagnosis and treatment of shock (Williams and Willkins, Baltimore 1967).

23. WEISSBACH, G. et al.: Fibrinolysis and consumption coagulopathy in newborns with respiratory distress syndrome (RDS). Abstracts Second Haematol. Meeting, Viemna, p. 267 (1973). 